\title{
The Effectiveness of Gelfoam Technique before Percutaneous Vertebroplasy: Is It Helpful for Prevention of Cement Leakage? A Prospective Randomized Control Study
}

\author{
Jae-Sang Oh, Jae-Won Doh, Jai-Joon Shim, Kyeong-Seok Lee, \\ Seok-Mann Yoon, Hack-Gun Bae \\ Department of Neurosurgery, Soonchunhyang University Cheonan Hospital, Cheonan, Korea
}

Objective: Preinjection gelfoam embolization during percutaneous vertebroplasty (PVP) has been thought alternative technique to prevent the leakage of bone cement. The goal of this study was to evaluate whether the gelfoam techniques are useful to reduce bone cement leakage.

Methods: Total 100 PVPs of osteoporotic spine compression fractures were performed by 1 spine surgeon who experienced more than 500 PVP cases under prospective control study. Operation was done in T-L junction (T10-L2) fractures with bitranspedicular approach. Preinjection gelfoam PVP was done in the 50 levels. As control group, PVP without gelfoam was done in the 50 levels. We did not perform preoperative venography. We inserted normal saline-mixed gelfoam to the anterior third of vertebral body via PVP needle, and then $3 \mathrm{~mL}$ of polymethylmetacrylate (PMMA) was injected. We prospectively evaluated the incidence and leakage pattern of PMMA by postoperative computed tomography.

Results: Between gelfoam and control groups, there were 11 leaks (22\%) versus 12 leaks (26\%). The mean operation time was 7.00 minutes versus 6.30 minutes. In gelfoam group, there were 6 spinal canal leaks, 4 paravertebral venous leaks, and 1 soft tissue leaks. In control group, there were 4 spinal canal leaks, 8 paravertebral venous leaks, and 1 disc space leak. In spite of cement leakage, there was no symptomatic case in both groups. Statistically, gelfoam technique was not related to decrease the incidence of leakage $(p=0.64)$.

Conclusion: Our prospective study showed that it did not significantly decrease cement leakage when vertebroplasty is performed by experienced spine surgeon.

Key Words: Vertebroplasty $\cdot$ Gelfoam $\cdot$ Osteoporotic fracture $\cdot$ Spine fractures

\section{INTRODUCTION}

Osteoporotic vertebral fracture can make severe problem, such as severe, debilitating back pain, decreased physical function and deformity ${ }^{10)}$. There are many options of nonoperative treatment of vertebral fracture: bed rest, orthotics, and analgesic medication. The patients who have persistent pain and decreased vertebral body height should be considered the percutaneous vertebroplasty (PVP).

Many articles were reported that PVP makes the pain relief in most patients who had osteoporotic compression fracture,

\footnotetext{
- Received: October 9, 2015 • Revised: May 18, 2016

- Accepted: June 7, 2016

Corresponding Author: Jae-Won Doh

Department of Neurosurgery, Soonchunhyang University Cheonan

Hospital, 31 Suncheonhyang 6-gil, Dongnam-gu, Cheonan 31151, Korea

Tel: +82-41-570-3652, Fax: +82-41-572-9297

E-mail: metatron1324@naver.com

$\otimes$ This is an open access article distributed under the terms of the Creative Commons Attribution Non-Commercial License (http://creativecommons.org/licenses/by-nc/4.0/) which permits unrestricted non-commercial use, distribution, and reproduction in any medium, provided the original work is properly cited.
}

and in $58 \%-86 \%$ had malignancy ${ }^{1,3,6,7)}$. And pain relief was remarkably decreased in 1 week $^{1,4)}$.

Although PVP is very easy and does not need to good experience, sometimes it makes a serious complication. Occasionally, patients will suffer more painful radiculopathy after treatment. In addition, the more serious complications are usually secondary to extravasation of cement. Extravasation can occur to several sites such as basivertebral vein, epidural vein, venous plexus, and epidural space. Among them, that to epidural space can compress spinal cord and nerve root.

Preinjection of gelfoam for embolization during PVP has been thought alternative technique to prevent the leakage of bone cement. But there was no prospective gelfoam study which compared with no gelfoam PVP. The goal of this study was to evaluate whether the gelfoam techniques are useful to reduce bone cement leakage during conventional vertebroplasty.

\section{MATERIALS AND METHODS}

Total 96 PVPs of thoracolumbar (T10-L2) osteoporotic spine compression fractures were performed by only 1 spine surgeon who experienced more than 500 PVP cases from 
2009 to 2013. Operation was done in T-L junction (T10-L2) fractures with bitranspedicular approach. Preinjection gelfoam PVP was done 50 levels. As control group, conventional PVP without gelfoam was done in the 50 levels. All procedures did not perform preoperative venography. Under fluoroscopic guidance, we inserted contrast-wet gelfoam to the anterior third of vertebral body via PVP needle, and then $3 \mathrm{~mL}$ of polymethylmetacrylate (PMMA) was injected. We prospectively evaluated the incidence and leakage pattern of PMMA by postoperative computed tomography (CT) scan.

\section{Patients' Selection}

Total 279 PVPs of thoracic and lumbar osteoporotic compression fractures were performed by 1 spine surgeon from 2009 to 2013. Among these, 100 cases were located from T10 to L2, and this diagnosis was osteoporotic compression fracture. We excluded the malignancy, infection, and a case of no osteoporosis. Inclusion criteria were as follows: first, severe back pain and local tenderness above visual analog scale 5 at least 2 weeks were not responding to analgesic medication or opioid drugs; second, local tenderness was matched at the level of abnormal signal intensity on fat-suppression sagittal T2 magnetic resonance imaging; third, we only involved on from T10 to L2 level. The reason that we limited on thoracolumbar junction (T10-L2) is known as vulnerable area which is the transitional zone of the spine and in adults the part of spinal cord so that canal encroachment can have significant neurologic complication.

We classified into the 2 groups; group 1 (no gelfoam) were 50 levels and group 2 (gelfoam) were 50 levels.

\section{Procedures}

PVP was performed under the local anesthesia on our intervention room using biplane $\mathrm{C}$-arm guided. The patients positioned prone, and the back was draped. The anteroposterior and lateral planes of $\mathrm{C}$-arm made the operative level on spine magnified for exact needling. Under the image guided, the Jamshidi needle was introduced gently with bipedicular approach and it was positioned in the anterior third of the vertebral body. We did not use the venography.

Next, gelfoam embolization was performed. A $10 \times 7 \times 0.05$ $\mathrm{cm}$ sheet of sterile absorbable gelatin sponge (SPONGOSTAN, Johnson \& Johnson, Skipton, UK) was used for embolization. After the gelatin sponge was cut into fine pieces (approximately $\left.1-2 \mathrm{~mm}^{2}\right)$ in the bowl, these were mixed with $10 \%$ contrast. Using the 10-mL syringe, all of these was active repeatedly mixed for evenly spreading. Without venogram, $3 \mathrm{~mL}$ of all mixed gelfoam was injected through each needle.

Last, $1.5 \mathrm{~mL}$ of vertebroplasty cement was injected through each needle. Total 3-mL vertebral cement was per level. All patients were achieved with bipedicular approach.

\section{Outcomes}

Because we use the biplane C-arm, so immediately result could be gained whether leakage or not. And 3 hours later CT was accessed to decide exact leakage or not and pattern distribution. Two spine surgeons were evaluated whether the leakage or not and its pattern.

\section{Leakage Pattern Classification}

Many articles were reported many leakage patterns using one's own reason. We created the new leakage pattern type. Type 1 is leaked into the spinal canal (SC). Type 2 is leaked into the paravertebral vein (PVV). Type 3 is leaked into the paraspinal muscle and soft tissue (ST). And type 4 is leaked into the disc space.

\section{Statistical Analysis}

All statistical comparisons were computed using SPSS ver. 14.0 (SPSS Inc., Chicago, IL, USA). Data are presented as the mean \pm standard deviation (SD). A t-test, chi-square test, and multivariate logistic regression analysis were used for statistical analysis. Null hypothesis of no difference were rejected if $\mathrm{p}$-values were less than 0.05 .

\section{RESULTS}

Two groups comprised of total 100 levels (93 patients). These are consisted of 25 males, 75 females: mean age, 72

Table 1. Demographics of patients and distribution of treated vertebrae

\begin{tabular}{lcccc}
\hline \hline Variable & $\begin{array}{c}\text { Group 1 } \\
\text { (no gelfoam) }\end{array}$ & $\begin{array}{c}\text { Group } 2 \\
\text { (gelfoam) }\end{array}$ & Total p-value \\
\hline No. of levels & 50 & 50 & 100 & \\
No. of patients & 46 & 47 & 93 & \\
Sex & & & & $>0.05$ \\
$\quad$ Male & 12 & 13 & 25 & \\
Female & 38 & 37 & 75 & \\
Age (yr) & $72.8 \pm 9.4$ & $72.9 \pm 8.5$ & & $>0.05$ \\
No. of each level & & & & \\
T10 & 3 & 2 & 5 & \\
T11 & 6 & 4 & 10 & \\
T12 & 16 & 11 & 27 & \\
L1 & 20 & 24 & 44 & \\
L2 & 5 & 9 & 14 & \\
Bone mineral density & -3.4 & -2.9 & & $>0.05$ \\
Remain rate (\%) & $76.4 \pm 18.9$ & $78.3 \pm 17.9$ & & $>0.05$ \\
\hline
\end{tabular}

Values are presented as number or mean \pm standard deviation. 
Table 2. Comparison of incidence of bone cement leakage between the 2 groups

\begin{tabular}{lccc}
\hline \hline Leakage & $\begin{array}{c}\text { Group 1 } \\
\text { (no gelfoam) }\end{array}$ & $\begin{array}{c}\text { Group 2 } \\
\text { (gelfoam) }\end{array}$ & p-value \\
\hline No leakage & $37(74)$ & $39(78)$ & \\
Leakage & $13(26)$ & $11(22)$ & $>0.05$ \\
Total & 50 & 50 & \\
\hline
\end{tabular}

Values are presented as number (\%).

Table 3. Distribution of leakage type between the 2 groups

\begin{tabular}{cccc}
\hline \hline Leakage type & $\begin{array}{c}\text { Group 1 } \\
\text { (no gelfoam) }\end{array}$ & $\begin{array}{c}\text { Group 2 } \\
\text { (gelfoam) }\end{array}$ & p-value \\
\hline 1 & 4 & 6 & $>0.05$ \\
2 & 8 & 4 & \\
3 & 0 & 1 & \\
4 & 1 & 0 & \\
Total & 13 & 11 &
\end{tabular}

Type 1, spinal canal; type 2, paravertebral vein; type 3, soft tissue; type 4 , disc space.

years; mean remain rate, 77\%; mean bone mineral density (BMD), -3.4. All patients had no symptomatic complication. And the most common level was L1. On baseline characteristics, there was no significant difference between the 2 groups in comparison of mean age, mean $\mathrm{BMD}$, mean remain rate of fractured spine $(\mathrm{p}>0.05)$ (Table 1).

There were 24 cement leakage of 100 levels (24\%). 13 leaks out of 50 levels (26\%) in group 1, and 11 of 50 levels (22\%) in group 2 . There was no statistical significant difference between the 2 groups in comparison of leakage occurrence $(p=$ 0.64 , chi-square test, Table 2).

In distribution of leakage type between the two groups, most common leakage type was 2 in group 1 and 1 in group 2 . In group 1, there were 4 in type 1,7 in type 2, and 1 in type 4. In group 2, there were 6 in type 1, 4 in type 2, and 1 in type 3 . There are no significant difference between the 2 groups in comparison of SC leakage occurrence ( $p>0.05$, chi-square test, Table 3). The mean operation time was 6.30 minutes versus 7 minutes on groups 1 and $2(p>0.05)$.

\section{DISCUSSION}

Vertebral compression fractures affect at least one-fourth of all postmenopausal women ${ }^{8)}$. And the risk of osteoporotic compression fracture increases significantly with age regardless of sex. Especially, 85-year-old woman has 6 times higher incidence than postmenopausal woman ${ }^{9,10)}$. Women with a history of osteoporotic vertebral compression fracture have a 5fold risk of developing subsequent compression fracture ${ }^{11)}$. Although our study was limited on osteoporotic vertebral compression fracture, $75 \%$ were female and mean $\mathrm{BMD}$ was -3.14 (SD, \pm 1.3$)$.
PVP has been introduced as an effective, minimal invasive procedure for the treatment of osteoporotic compression fracture $^{2)}$. The purpose of this study was to know if routine gelfoam embolization before the bone cement injection was safe and feasible to reduce the incidence of leakage. Our study showed the incidence of bone cement leakage after gelfoam embolization tended to be decreased in compared with control group ( $23.4 \%$ vs. $39 \%, \mathrm{p}>0.05)$. PVP with gelfoam embolization is well-known for a feasible treatment modality to reduce the incidence of cement leakage. But it was not a comparative result with simple PVP without using gelfoam as our study. We think the reason there were no statistical significant difference between the 2 groups in comparison of leakage occurrence is the insufficient number of cases. In comparing our results with other literatures, our leakage rate on gelfoam embolization was relatively low. Cortet et al. ${ }^{3)}$ found that incidence of cement leakage after PVP was $72.5 \%$, usually into the paraspinal ST (52.5\%).

We hypothesis that leakage types of PVV or SC was reduced on gelfoam PVP, and it could prevent the pulmonary embolism or cord compression. However, there was no significant difference on leakage type between the 2 groups. The reason why we study the PVV is that bone cement leakage makes easily venous leakage than artery occlusion.

Our study had some limitations. First, all PVP were performed by only 1 spine surgeon who experienced more than 500 PVP cases. Because PVP is not high level of difficulty and good skilled spine surgeon has many experiences to reduce the leakage of bone cement, the result may show no significant difference. If operations were performed by the beginner of young spine surgeon, there is no saying how the result will be. Second, the total PVP 100 procedures were small. We limited on the T10-L2 spine level, BMD score $(<-2.5)$, and only 1 spine surgeon for the high degree of accuracy. The reason excluded the lower lumbar spine is that lower lumbar have different clinical characteristics ${ }^{5)}$. Third, although Ross et al. ${ }^{11)}$ reported that cortical fracture of fractured spine could affect the incidence of bone cement leakage, we did not involve these in our study.

We are studying the usefulness of gelfoam embolization with venography under the randomized control study. And we expect that this advanced technique could reduce the incidence of bone cement leakage during PVP.

\section{CONCLUSION}

Although technique of gelfoam embolization before PVP has been thought to be an effective procedure to decrease the cement leakage, our prospective study showed that it did not significantly decrease cement leakage when vertebroplasty is performed by experienced spine surgeon. In addition, gelfoam embolization before PVP did not significantly reduce the SC leakage which induces the severe neurologic complication. We think that this technique needs the further evaluation in unexperienced spine neurosurgeon or resident. 


\section{CONFLICT OF INTEREST}

No potential conflict of interest relevant to this article was reported.

\section{ACKNOWLEDGMENTS}

This research was supported by Soonchunhyang University Research Fund.

\section{REFERENCES}

1. Barr JD, Barr MS, Lemley TJ, McCann RM: Percutaneous vertebroplasty for pain relief and spinal stabilization. Spine (Phila Pa 1976) 25:923-928, 2000

2. Cohen LD: Fractures of the osteoporotic spine. Orthop Clin North Am 21:143-150, 1990

3. Cortet B, Cotten A, Boutry N, Dewatre F, Flipo RM, Duquesnoy $\mathrm{B}$, et al: Percutaneous vertebroplasty in patients with osteolytic metastases or multiple myeloma. Rev Rhum Engl Ed 64:177-183, 1997

4. Grados F, Depriester C, Cayrolle G, Hardy N, Deramond H,
Fardellone P: Long-term observations of vertebral osteoporotic fractures treated by percutaneous vertebroplasty. Rheumatology (Oxford) 39:1410-1414, 2000

5. Han S, Park HS, Pee YH, Oh SH, Jang IT: The clinical characteristics of lower lumbar osteoporotic compression fractures treated by percutaneous vertebroplasty: a comparative analysis of 120 cases. Korean J Spine 10:221-226, 2013

6. Jensen ME, Evans AJ, Mathis JM, Kallmes DF, Cloft HJ, Dion JE: Percutaneous polymethylmethacrylate vertebroplasty in the treatment of osteoporotic vertebral body compression fractures: technical aspects. AJNR Am J Neuroradiol 18:1897-1904, 1997

7. Kim AK, Jensen ME, Dion JE, Schweickert PA, Kaufmann TJ, Kallmes DF: Unilateral transpedicular percutaneous vertebroplasty: initial experience. Radiology 222:737-741, 2002

8. Kim DH, Vaccaro AR: Osteoporotic compression fractures of the spine; current options and considerations for treatment. Spine J 6:479-487, 2006

9. Lane JM, Nydick M. Osteoporosis: current modes of prevention and treatment. J Am Acad Orthop Surg 7:19-31, 1999

10. Old JL, Calvert M: Vertebral compression fractures in the elderly. Am Fam Physician 69:111-116, 2004

11. Ross PD, Davis JW, Epstein RS, Wasnich RD: Pre-existing fractures and bone mass predict vertebral fracture incidence in women. Ann Intern Med 114:919-923, 1991 